\title{
Continuous Culture of Some Anaerobic and Facultatively Anaerobic Rumen Bacteria
}

\author{
By P. N. HOBSON \\ Rowett Research Institute, Bucksburn, Aberdeen
}

(Received 10 March 1964)

\begin{abstract}
SUMMARY
Strains of Streptococcus bovis, Selenomonas ruminantium, and an anaerobic lipolytic bacterium $(5 \mathrm{~s})$ have been grown under carbohydratelimiting conditions in continuous culture for long periods. With S. ruminantium and bacterium $5 \mathrm{~s}$ the fermentation products varied with growth rate. Yield of organism in continuous culture of all three bacteria showed a maximum at a particular growth rate. The yield of $S$. ruminantium was much higher in continuous culture at optimum growth rate than in batch culture, and was also higher than can be explained on present concepts of the energy from fermentation available for growth. The various results are discussed in the light of results obtained with other bacteria and the conditions obtaining in the rumen.
\end{abstract}

\section{INTRODUCTION}

During the development of the culture apparatus described in the previous paper (Hobson, 1965) a strain of Selenomonas ruminantium was used because it is an anaerobic rumen bacterium and the strain had been well characterized in previous work (Hobson \& Mann, 1961). It has been suggested that selenomonads are not bacteria, but should be classed as protozoa (e.g. Bisset \& Davis, 1960). However, apart from other considerations, our own unpublished results show that the cellwall composition of $S$. ruminantium strain 6 (nitrogen $10.0 \%$; carbohydrate $4.7 \%$; lipid $28 \%$; hexosamine $3.6 \%$; ash $0.7 \%$; phosphorus $0.7 \%$; with twelve amino acids present) is similar to that of other Gram-negative bacterial cell walls. This seems to be an additional reason for regarding the selenomonads as bacteria. When the unusual nature of the results with $S$. ruminantium in the present work became apparent some runs were done with a rumen strain of Streptococcus bovis, to examine the behaviour of a facultatively anaerobic organism which ferments the same carbohydrate. Finally, the lipolytic bacterium $5 \mathrm{~s}$ was used in an extended series of tests; the reasons for this were twofold. First, bacterium $5 \mathrm{~s}$ is also a strict anaerobe, but it ferments a simpler carbohydrate than does the selenomonad S. ruminantium. (This selenomonad lost the ability to ferment glycerol on prolonged growth on glucose.) Secondly, large amounts of organisms were needed for experiments on the lipolytic activity of bacterium $5 \mathrm{~s}$. The strains of anaerobic bacteria used would grow only in media containing amino acid mixtures, and not on simpler media containing only ammonia as nitrogen source as do some rumen bacteria. While a simpler medium might have been desirable for some aspects of the work the yields of bacteria have generally been determined for media in which were present most of the monomers of cell constituents. 
The symbols used in this paper to describe growth in continuous culture are those of Herbert, Elsworth \& Telling (1956). The yield constant, $\boldsymbol{Y}_{\text {gluc }}$ or $\boldsymbol{Y}_{\text {glyc }}$, is g. dry weight organism/mole substrate utilized, as introduced by Bauchop \& Elsden (1960).

\section{METHODS}

\section{Organisms used}

Streptococcus bovis. This was the strain $18 \mathrm{c} 6$ isolated from the sheep rumen described by Hobson \& Mann (1955). Stock cultures were kept in Robertson's cooked meat medium or were freeze-dried.

Selenomonas ruminantium var. lactyliticas. This was the strain 6 isolated from the rumen and described by Hobson \& Mann (1961). On original isolation and for some time after it rapidly fermented glycerol. At the time of the present experiments various cultures had been kept as stocks and continually subcultured on glucose slopes, and other cultures had been kept on glucose and then freeze-dried. On retesting, after the experiments on continuous culture on glucose had been done (some 3 years after isolation of the organism), it was found that neither stock cultures on glucose slopes nor the revived freeze-dried cultures metabolized glycerol to any extent. A little growth was obtained on the basal constituents of the medium, but continued subculture on liquid or solid media containing glycerol did not increase the growth or glycerol utilization.

Lipolytic bacterium. This organism, bacterium $5 \mathrm{~s}$, was isolated from a sheep on a hay and concentrate diet. It was similar in all respects, except that it fermented the additional carbohydrate cellobiose, to the lipolytic bacteria previously isolated from sheep (Hobson \& Mann, 1961). These bacteria do not ferment glucose. Stock cultures were kept on glycerol slopes at $2^{\circ}$, and were subcultured every 2 weeks. No change in the characteristics of the strain were noted during the period of the experiments.

\section{Media}

For selenomonad strain 6. The medium used (CY medium) initially was one containing mineral solutions $(a)$ and $(b), 15 \mathrm{ml}$. each; Bacto Casitone, 1.5 g.; Bacto Yeast Extract, 0.25 g.; $\mathrm{NaHCO}_{3}, 0.4 \mathrm{~g}$.; cysteine $\mathrm{HCl}, 0.05$ g.; resazurin, $0.1 \mathrm{ml}$. of $0 \cdot 1 \%(\mathrm{w} / \mathrm{v})$ solution; water to $100 \mathrm{ml}$. and glucose in the correct concentration. The constituents of mineral solutions $(a)$ and $(b)$ and the methods of preparing the media under oxygen-free carbon dioxide were described by Hobson $\&$ Mann (1961). This medium was used solidified with agar for stock cultures, and as liquid for batch cultures of the selenomonad. The medium for continuous cultures was originally the CY medium + glucose, but in later experiments this was changed by addition of $0.522 \mathrm{~g} . \mathrm{K}_{2} \mathrm{HPO}_{4}$ and $0 \cdot 272 \mathrm{~g}$. $\mathrm{KH}_{2} \mathrm{PO}_{4} / 100 \mathrm{ml}$. (CYP medium; $\mathrm{pH} \mathrm{6.7).}$

For lipolytic bacterium $5 \mathrm{~s}$. Initial experiments were made with medium $\mathrm{CY}$ with glycerol added. Later experiments used a medium (AHI medium) of composition: mineral solution ( $a$, above), without $\mathrm{NaCl}, 15 \mathrm{ml}$.; solution ( $b$, above), $15 \mathrm{ml}$; acidhydrolysed casein (Allen and Hanbury, London), 1 g.; Bacto Yeast Extract, 1 g.; $\mathrm{NaHCO}_{3}, 0.4$ g.; cysteine $\mathrm{HCl}, 0.05$ g.; resazurin solution, $0.1 \mathrm{ml}$. of $0.1 \%$ solution; glycerol; water to $100 \mathrm{ml}$. The casein hydrolysate gave an acid solution, so the minerals, casein hydrolysate, yeast extract and water were mixed and the solution 
adjusted to $\mathrm{pH} 6 \cdot 8$ with a little $10 \mathrm{~N}-\mathrm{NaOH}$. At this $\mathrm{pH}$ value a faint opalescence developed; increasing the $\mathrm{pH}$ value caused a precipitate to form. The resazurin (and the agar when slopes were being made) was added, and the solution then autoclaved and a filter-sterilized solution of bicarbonate + cysteine + glycerol added in the usual way (Hobson \& Mann, 1961). A heavy opalescence formed in the autoclaved medium, but this cleared as the medium cooled; the slight sediment remaining was allowed to settle before the medium, prepared in bulk, was dispensed into smaller portions for batch cultures. In the continuous cultures this sediment settled to the bottom of the medium flasks, leaving a clear supernatant fluid; this sediment was not disturbed as medium flowed between the flasks or into the culture vessel. For the later continuous culture work the sodium bicarbonate concentration was increased to $0 \cdot 6 \%$, and the cysteine concentration to $0.1 \%$. The medium was of $\mathrm{pH}$ 6.8, and this is referred to as $\mathrm{AH} 2$ medium. The $\mathrm{NaCl}$ was omitted from these media as other experiments suggested that a better production of lipase occurred in the absence of $\mathrm{NaCl}$.

Streptococcus bovis. This was grown in the CYP medium.

All cultures were incubated at $39^{\circ}$.

\section{Analytical methods}

Glucose was determined by an anthrone method, as was bacterial carbohydrate. Glycerol was determined by the method of Hanahan \& Olley (1958). Volatile fatty acids were steam-distilled from the culture media, and the constituent acids identified by paper chromatography. These methods and that for lactic acid were previously described (Hobson \& Mann, 1961). The fermentation acids were separated quantitatively on Celite columns by the method of Wiseman \& Irwin (1957). This method did not separate lactic and succinic acids completely, so the total lactic + succinic fraction was determined by the column separation and succinic acid determined by subtracting from this a value for lactic acid determined on another portion of the culture.

Organism dry weights were determined by centrifuging $10 \mathrm{ml}$. of culture in a small conical tube, washing the sediment once with $10 \mathrm{ml}$. distilled water, again centrifuging, and finally drying the sediment to constant weight at $110^{\circ}$ after removing most of the water.

The 'turbidity' of cultures was measured in $1.5 \mathrm{ml}$. tubes in an EEL colorimeter (Evans Electroselenium Ltd., Harlow, Essex) with an OR 1 (640 $\mathrm{m} \mu$ ) filter. Experiments with bacterial suspensions showed that the red filter gave better linearity with amount of organisms, and covered a wider range, than did blue or yellow filters. The turbidity values were read in the EEL colorimeter on a scale 0-10-100- $\infty$. Measurements of organism dry weight/unit volume and turbidity as EEL colorimeter readings were made during batch and continuous cultures. The measurements for each organism fell on the same straight line (Fig. 1). Deviations were found only in cultures where lysis of organisms was taking place or during granular growth. The turbidity was thus routinely used as a measure of the behaviour of the continuous cultures and in some cases to estimate yields of organisms.

The sizes of organisms were measured in wet preparations examined with a calibrated micrometer eyepiece in phase-contrast illumination. The sizes of ten 
bacteria taken at random in a field were measured and an average length found; this was repeated at each sampling time.

A Pye $\mathrm{pH}$ meter was used to measure $\mathrm{pH}$ value as soon as possible after removal of a sample from the culture vessel.

\section{RESULTS}

General. Batch cultures were inoculated from overnight cultures, the volume of inoculum usually being about $2 \%$ of the culture volume. The continuous culture apparatus was assembled with medium as previously described, inoculated and allowed to grow as a batch culture overnight. This did not usually give the maximum growth attainable in a small batch culture. The culture was then sampled and

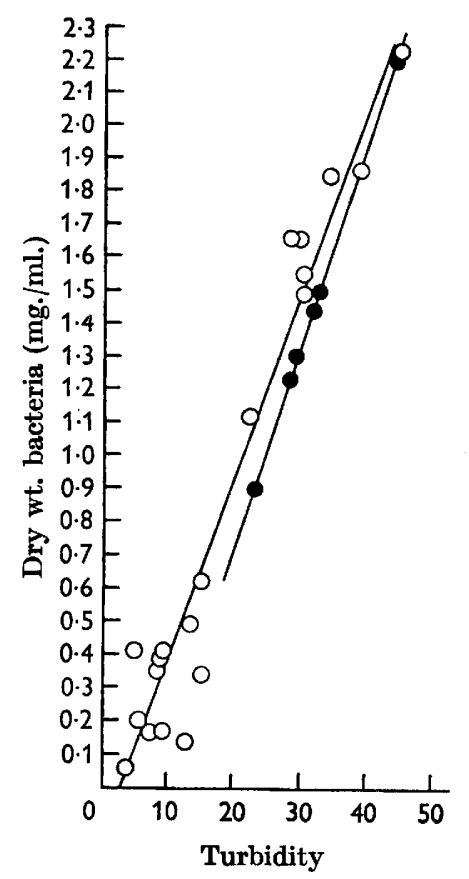

Fig. 1

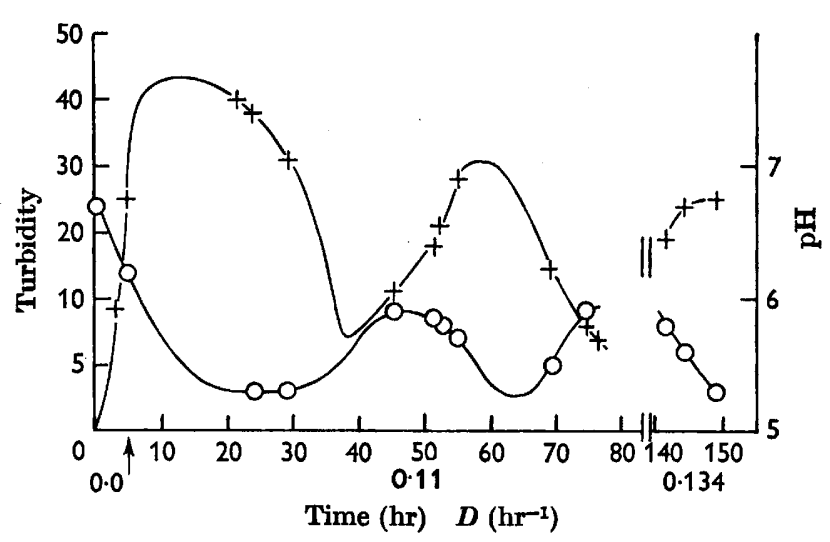

Fig. 2

Fig. 1. The relationship of bacterial dry weight and turbidity in batch and continuous cultures of selenomonad $6(O)$ and lipolytic bacterium $5 \mathrm{~s}(O)$. Turbidity of basal medium = 1-1.5. A turbidity of 30 EEL units $=1.49 \mathrm{mg}$. dry wt. $/ \mathrm{ml}$. for selenomonad 6 .

Fig. 2. Growth of lipolytic bacterium strain $5 \mathrm{~s}$ in an insufficiently buffered medium. Glycerol concentration $65.6 \mu \mathrm{mole} / \mathrm{ml}$. Turbidity measured on an EEL colorimeter, +, culture. $\mathrm{pH}, \mathrm{O}$.

the inlet pump started at a suitable rate. The turbidity reading on the EEL colorimeter always decreased in the first few hours after starting the medium flow and then returned to a value corresponding to the dilution rate. Measurements of turbidity were made at intervals and a further sample taken for analysis when the culture had been stable for about $30 \mathrm{hr}$ in most cases at high dilution rates, or about $72 \mathrm{hr}$ or longer at low dilution rates. Since there was a slight variation in turbidity with time the value shown in the figures for turbidity at any dilution rate is an 
average of the values found over the steady-state period. As the volume of culture needed to obtain turbidity and pH measurements was about $1.5 \mathrm{ml}$., this was a little over $1 \%$ of the culture volume and so did not affect the system. When about $10 \mathrm{ml}$. was taken for analysis the culture was not sampled again for a few hours, depending on the dilution rate, to allow return to steady-state conditions. No difficulties have been experienced with 'wall growth' with the three types of bacterium tested.

Stability of the apparatus. The cultures ran for long periods with a minimum of attention beyond an occasional adjustment of the $\mathrm{CO}_{2}$ flow, and the apparatus was routinely left to run overnight, and occasionally over a weekend, without attention. The stability of the medium flow has been shown previously. Because of the great dependence of turbidity of the selenomonad culture on dilution rate a rather greater variation in turbidity readings during running at one nominal dilution rate was found than for other organisms, because of slight variations in pumping speed. With the bacterium $5 \mathrm{~s}$ in a test run of $200 \mathrm{hr}$ at one dilution rate the turbidity readings, measured at about equal intervals, were $23 \cdot 2,22 \cdot 5,22 \cdot 4,21 \cdot 1,21 \cdot 1,21 \cdot 1$, $21 \cdot 1,20 \cdot 0,22 \cdot 6,22 \cdot 6,23 \cdot 3,23 \cdot 6$. This period included a change of medium in the 5 l. reservoir.

$p H$ stability. In initial experiments with the bacterium $5 \mathrm{~s}$ the medium $\mathrm{AH} 1$ was not sufficiently buffered. Fig. 2 shows two sections from a graph of the results obtained. A number of dilution rates were tested and in each case the cycle was repeated, the time scale being slightly shorter at higher dilution rates. All the glycerol in the medium had been utilized at the times of maximum turbidity and minimum $\mathrm{pH}$ value. It is evident that a comparatively small change in $\mathrm{pH}$ value markedly decreased the growth rate of the bacteria and they were washed out until the entry of fresh medium restored the $\mathrm{pH}$ value, when growth and fermentation started, and the cycle was repeated. Small changes in $\mathrm{pH}$ value may have been partly responsible for the slight variations in turbidity found in other experiments during steady states. Finn \& Wilson (1954) suggested that cycling of a yeast culture was due to $\mathrm{pH}$ variations. With the medium $\mathrm{AH} 2$ the $\mathrm{pH}$ value was steadier, the fluctuations over $70 \mathrm{hr}$ being, for example, pH: 5.9, 6.0, 5.9, 5.9, 6.1, 6.0. The selenomonad cultures with medium CYP fluctuated between $\mathrm{pH} 6 \cdot 1$ and $6 \cdot 2$.

As a further example of the effect of an insufficiently buffered medium the Streptococcus bovis strain 18c6 was grown in a yeast medium with glucose (Hobson \& Mann, 1955). In batch cultures the $\mathrm{pH}$ value fell rapidly and there was little correspondence between turbidity and glucose concentration except at low glucose concentrations. In continuous culture the $\mathrm{pH}$ value fell to about 4.9 (from 6.0) and the turbidity (at three dilution rates) to less than half that initially obtained in batch culture. All the glucose was not utilized.

\section{Growth of Streptocococcus bovis $18 \mathrm{c} 6$}

In batch cultures grown in CYP medium with glucose 11.1, 22.2, 33.3, 44.4 and $55.5 \mu \mathrm{mole} / \mathrm{ml}$. growth was proportional to glucose added between $22 \cdot 2$ and 44.4 $4 \mu \mathrm{mole} / \mathrm{ml}$. and virtually all the glucose was used; at $55.5 \mu \mathrm{mole} / \mathrm{ml}$. a divergence of growth and glucose concentration was beginning. At glucose $11 \cdot 1 \mu \mathrm{mole} / \mathrm{ml}$,, although all the glucose was utilized, growth was higher than expected from the other results because of the contribution of growth on the basal medium. This effect was similar to that found with the selenomonad (Fig. 4). Fig. 3 shows the 
effect of dilution rate on growth taken from a run of $4.50 \mathrm{hr}$ with a medium with glucose $27 \cdot 7 \mu \mathrm{mole} / \mathrm{ml}$. The minimum doubling time $\left(t_{d}=\left(\log _{e} 2\right) / D\right)$ was about $0.5 \mathrm{hr}$. No intracellular 'starch' was observed in the organisms from continuous culture. This might be expected from previous experiments on starch formation in this organism (Hobson \& Mann, 1955).

\section{Growth of Selenomonas ruminantium strain 6}

Batch culture experiments were done to find the range over which concentration of organism varied with glucose concentration so that a glucose-limiting system might be used in continuous culture. The results of a number of experiments are shown in Fig. 3 and Table 1. These experiments were not always reproducible for

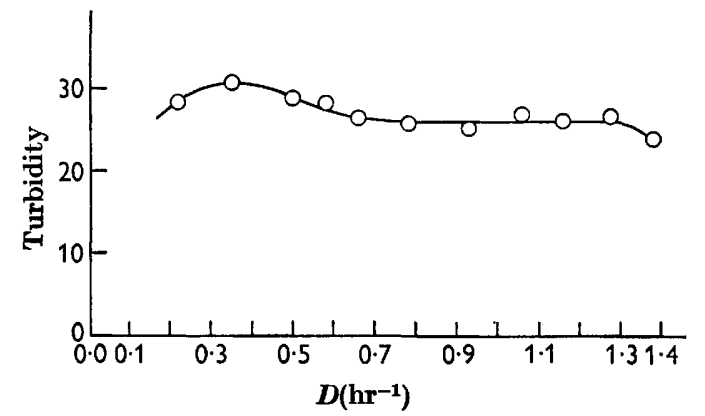

Fig. 3

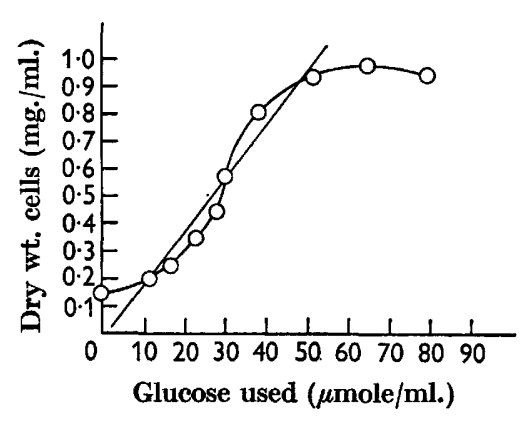

Fig. 4

Fig. 3. Continuous culture of Streptococcus bovis 18c6. Steady-state turbidity and dilution rate $(D)$. Glucose-limiting conditions, glucose concentration $27 \cdot 7 \mu \mathrm{mole} / \mathrm{ml}$. Maximum turbidity of batch cultures at same substrate concentration c. 22 .

Fig. 4. Growth of selenomonad 6 in batch cultures at various glucose concentrations.

two reasons. After maximum growth was attained the selenomonads tended to lyse fairly rapidly and the turbidity readings decreased. This rapid decrease in turbidity after maximum growth has been noted with other rumen bacteria in our own laboratories and by others (e.g. Bryant \& Robinson, $1961 a$ ). Also, when growth was slow the cultures often did not attain the maximum yield of a rapidly growing culture, although the glucose was utilized. The values for $Y_{\text {gluc }}$ given in Table 1 are uncorrected for growth on the basal medium as it does not seem possible to decide, either from Fig. 4 or a similar graph in which concentration of organism (mg. dry wt./ml.) was plotted against glucose added, whether growth on the basal medium was taking place or was suppressed in the presence of glucose. The results shown in Fig. 4 indicated that a glucose-limiting culture was possible with this basal medium at glucose concentrations about $27 \cdot 7 \mu \mathrm{mole} / \mathrm{ml}$. At the higher glucose concentrations another nutrient, or possibly the $\mathrm{pH}$ value, was becoming limiting in the batch cultures. Volatile fatty acids (VFA), identified as acetic and propionic by paper chromatography, and lactic acid, were produced in the glucose fermentation in the batch cultures. At glucose $27 \cdot 7 \mu \mathrm{mole} / \mathrm{ml}$. added, $27 \cdot 4 \mu \mathrm{mole}$ VFA and 186.6 $\mu$ mole lactic acid were produced per $100 \mu$ mole glucose utilized. Assuming that the VFA are acetic and propionic acids with $\mathrm{CO}_{2}$ equivalent to the acetic acid, 
this gives a carbon recovery of $107 \%$. At other concentrations of added glucose up to $83.3 \mu \mathrm{mole} / \mathrm{ml}$. the proportions of VFA and lactic acid were similar, and carbon recovery on the above basis was somewhat over, or somewhat under, $100 \%$. At higher concentrations of added glucose carbon recovery was low, being only about $60 \%$ at the highest concentration. The reason for this is not known, unless a large amount of glucose was converted to intracellular polysaccharide. The 'carbohydrate' content of the dried organisms at glucose $27 \cdot 7$ and $33 \cdot 3 \mu \mathrm{mole} / \mathrm{ml}$. added was 22 and $26 \%$ measured as apparent glucose by anthrone reagent, but no other determinations were made. If the glucose utilized but not recovered as fermentation products were assimilated then this would increase the low value of $\boldsymbol{Y}_{\text {gluc }}$ found at the highest glucose concentration.

Table 1. Batch growth of selenomonad 6 on glucose

$\begin{array}{cccc}\begin{array}{c}\text { Glucose added } \\ (\mu \mathrm{mole} / \mathrm{ml} .)\end{array} & \begin{array}{c}\text { Glucose used } \\ (\mu \mathrm{mole} / \mathrm{ml} .)\end{array} & \begin{array}{c}\text { Cell dry wt. } \\ (\mathrm{mg} \cdot / \mathrm{ml} .)\end{array} & \boldsymbol{Y}_{\text {gluc }}{ }^{*} \\ 0 & 0 & 0 \cdot 15 & - \\ 11 \cdot 1 & 11 \cdot 1 & 0 \cdot 20 & 18 \cdot 0 \\ 16 \cdot 6 & 16 \cdot 6 & 0 \cdot 25 & 15 \cdot 0 \\ 22 \cdot 2 & 22 \cdot 2 & 0 \cdot 35 & 15 \cdot 8 \\ 27 \cdot 7 & 27 \cdot 7 & 0 \cdot 45 & 16 \cdot 2 \\ 33 \cdot 3 & 29 \cdot 4 & 0 \cdot 58 & 19 \cdot 7 \\ 44 \cdot 5 & 37 \cdot 8 & 0 \cdot 81 & 21 \cdot 4 \\ 83 \cdot 3 & 51 \cdot 1 & 0 \cdot 94 & 18 \cdot 4 \\ 100 \cdot 0 & 64 \cdot 4 & 0 \cdot 98 & 15 \cdot 2 \\ 138 \cdot 9 & 78 \cdot 9 & 0 \cdot 94 & 11 \cdot 9\end{array}$

Medium as in text. Final $\mathrm{pH}$ in cultures containing glucose 5·6-5.7. *Not corrected for growth in basal medium, see text.

In the first continuous culture runs CY medium was used. This was initially at about $\mathrm{pH} 6 \cdot 5$, but during growth this fell to between $\mathrm{pH} 5.7$ and 6.0. This was felt to be rather low, so further runs were made with CYP medium initially at pH 6.7 and the culture remained at $\mathrm{pH} 6.1$ to 6.2 with glucose $27 \cdot 7 \mu \mathrm{mole} / \mathrm{ml}$. and pH 6.4 with $13.9 \mu \mathrm{mole} / \mathrm{ml}$. However, the results with CY medium and CYP medium all integrated. Figure 5, 6 and 7 show results taken from the steady-state values of five runs of $268 \mathrm{hr}, 721 \mathrm{hr}, 294 \mathrm{hr}, 143 \mathrm{hr}$ and $60 \mathrm{hr}$. The shortest run was to obtain two points at the higher dilution rates. In all runs the dilution rates examined overlapped with other runs. One run was with CY medium, the others with CYP medium. Points from one run $(290 \mathrm{hr})$ on CY medium with glucose $13.9 \mu \mathrm{mole} / \mathrm{ml}$. are included, as are points from a run of $130 \mathrm{hr}$ on the basal CY medium. The glucose concentration in the culture vessel, corrected for blank values of the basal medium, averaged $4 \%$ of the incoming glucose at glucose $27 \cdot 7 \mu \mathrm{mole} / \mathrm{ml}$. in the medium, and was virtually nil at $13.9 \mu \mathrm{mole} / \mathrm{ml}$., up to dilution rates $(D)$ of $0.465 \mathrm{hr}^{-1}$; no measurements were made above this dilution rate. At a number of times during cultivation the total volatile fatty acids were measured (Fig. 7). Only a few determinations of lactic acid were made. The value obtained at $D=0.1 \mathrm{hr}^{-1}$ was $7 \mu$ mole lactic/100 $\mu$ mole glucose utilized, at $D=0.26$ the value was $87 \mu$ mole and at $D=0.286$ the value was $73 \mu$ mole. These figures are obviously subject to errors; taking average values for the VFA formed at these dilution rates from Fig. 7 carbon recoveries of 96,104 and $94 \%$ are obtained. These figures thus show a change 
in the fermentation products with change in dilution rate and they also show that little of the glucose was incorporated into cellular material.

Measurement of the size of organisms during runs showed no variation in width, but the length varied somewhat from a minimum of $2 \cdot 1 \mu$ to a maximum of $4.0 \mu$, being generally about $3 \cdot 1 \mu$. No correlation between length of organism and dilution rate was observed. However, during some of the runs growth became very granular for a day or two. During the granular growth period very long organisms were seen which seemed to be undivided selenomonads. The granular growth returned to normal after a day or two and no reason for it could be found. The selenomonads varied in shape at times, some being almost straight rods, as compared

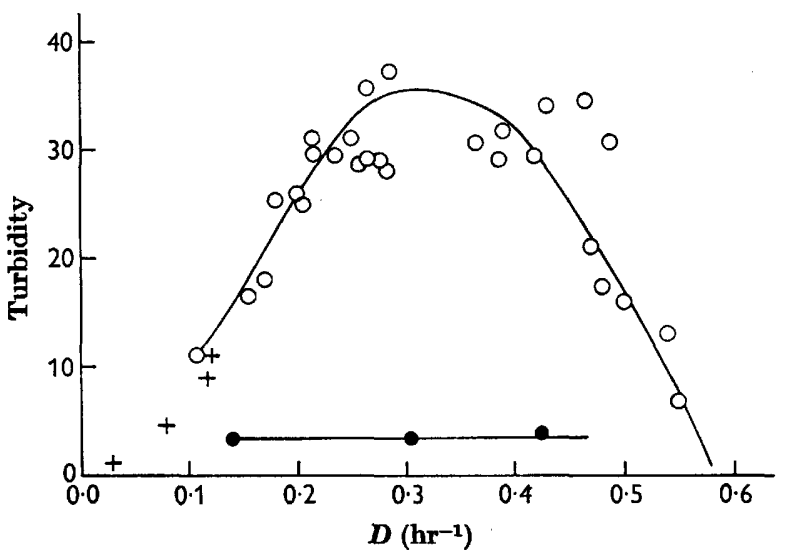

Fig. 5

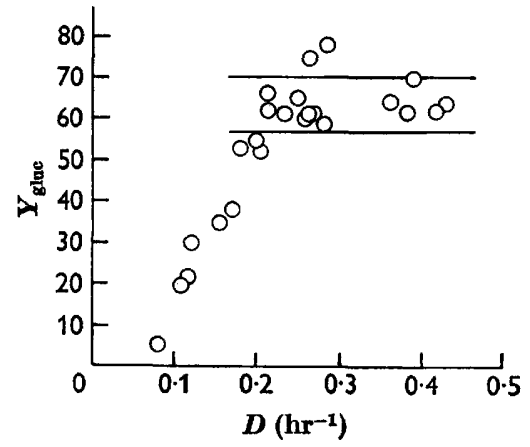

Fig. 6 .

Fig. 5. Continuous culture of selenomonad 6 ; relationship between turbidity and dilution rate $(D)$ at different steady states. Glucose-limiting conditions, glucose concentration $27.7 \mu$ mole $/ \mathrm{ml}$. $0,13.9 \mu$ mole $/ \mathrm{ml}$. + , basal medium $O$. The values for $27.7 \mu \mathrm{mole} /$ $\mathrm{ml}$. glucose are from five runs, and with these and the ones for $13.9 \mu \mathrm{mole} / \mathrm{ml}$. glucose the values are corrected for growth in the basal medium. At dilution rates up to $0 \cdot 465 \mathbf{h r}^{-1}$ an average of $96 \%$ of the glucose was being utilized. No measurements were made above this dilution rate. Maximum turbidity of batch cultures at $27 \cdot 7 \mu$ mole glucose/ml. c. 11 .

Fig. 6. Continuous culture of selenomonad 6; relationship between $Y_{\text {gluc }}$ and dilution rate $(D)$. Values are taken from five runs at $27 \cdot 7 \mu \mathrm{mole} / \mathrm{ml}$. glucose in the medium and one run at $13.9 \mu \mathrm{mole} / \mathrm{ml}$. glucose.

with the normal curved shape. The percentage of motile organisms was generally much higher in the continuous cultures than in batch cultures. Tests were made at intervals during all runs, especially when the percentage of straight organisms was high, for the reaction of the organisms with antisera specific to the selenomonads (Hobson, Mann \& Smith, 1962). In all cases good agglutination was observed.

\section{Culture of lipolytic bacterium 5 s}

The bacterium $5 \mathrm{~s}$ was originally grown in both batch and continuous culture in CY medium with various amounts of glycerol. In batch cultures the growth on the basal medium was high and at glycerol $65.2 \mu \mathrm{mole} / \mathrm{ml}$. only $52 \%$ of the glycerol was used; similar results were obtained in continuous culture. Further experiments showed that an amino acid mixture and yeast extract were needed for good growth 
and $1 \%(\mathrm{w} / \mathrm{v})$ casein hydrolysate $+1 \%$ yeast extract medium (see Methods, medium AH1) gave optimum growth and glycerol utilization; but to prevent the pH value cycling in the continuous culture, and to get a more reduced medium, the medium was slightly altered (medium AH2). The results of experiments with batch cultures (AHI medium) are shown in Table 2 ; the final $\mathrm{pH}$ value was $5 \cdot 1$ to

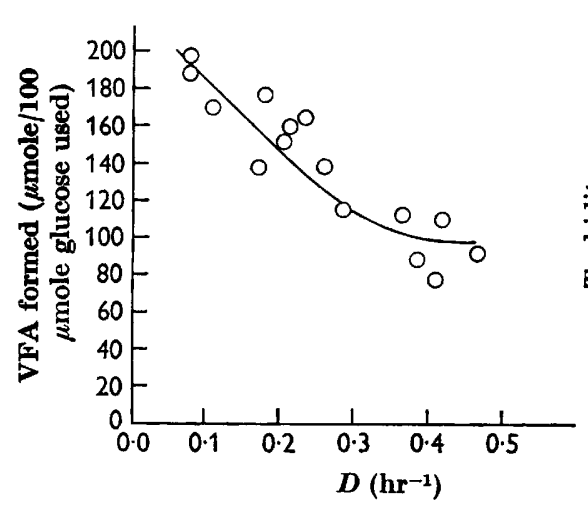

Fig. 7

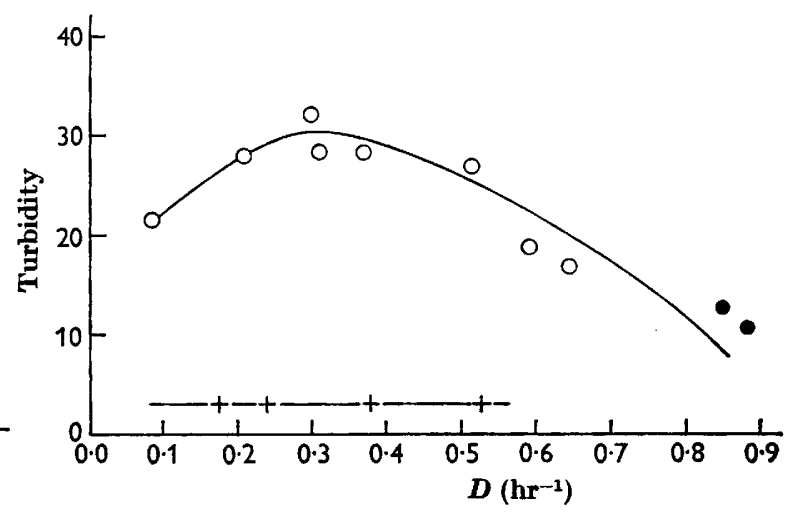

Fig. 8

Fig. 7. Continuous culture of selenomonad 6 ; relationship between VFA produced and dilution rate $(D)$. Values are taken from five runs at $27 \cdot 7 \mu \mathrm{mole} / \mathrm{ml}$. glucose in the medium and one run at $13.9 \mu \mathrm{mole} / \mathrm{ml}$. glucose.

Fig. 8. Continuous culture of lipolytic bacterium $5 \mathrm{~s}$; relationship between turbidity and dilution rate $(D)$ at different steady states. Glycerol-limiting conditions, glycerol concentration $65.6 \mu \mathrm{mole} / \mathrm{ml}$. $O$. At points marked a true steady state was not achieved; the density drifted downwards at about 1 unit per $12 \mathrm{hr}$. Basal medium growth + . At $D=0.083,98 \%$ of the glycerol was used, at $D=0.206,100 \%$; at $D=0.298$, $98.6 \%$; at $D=0.310,90.7 \%$; at $D=0.370,88.1 \%$; at $D=0.514,75.1 \%$; at $D=$ $0.591,64.3 \%$; at $D=0.850,53.6 \%$; at $D=0.883,36.5 \%$. The values are taken from two runs with glycerol and one run with the basal medium. Maximum turbidity of batch cultures at same substrate concentration $c$. 32 . A turbidity of $30 \mathrm{EEL}$ units $=1 \cdot 36$ mg. dry wt. bacteria/ml.

\section{Table 2. Batch growth of lipolytic bacterium strain 5 s on glycerol}

$\begin{gathered}\text { Glycerol } \\ \text { added } \\ (\mu \mathrm{mole} / \mathrm{ml} .)\end{gathered}$
0
$65 \cdot 2 \dagger$
$130 \cdot 4$
$195 \cdot 6$
$\mathbf{2 6 0 \cdot 8}$

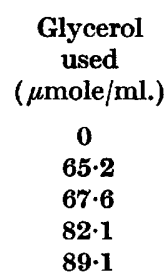

Dry wt.
bacteria
(mg./ml.)
$*$
1.48
$1 \cdot 36$
$1 \cdot 17$
1.30

$\begin{array}{cc} & \begin{array}{c}\text { VFA formed } \\ (\mu \text { mole } / 100\end{array} \\ Y_{\text {glye }} & \begin{array}{c}\mu \text { mole } \\ \text { glycerol used })\end{array} \\ - & - \\ \mathbf{2 2 \cdot 7} & 65 \cdot 5 \\ 20 \cdot 1 & 61 \cdot 4 \\ 14 \cdot 3 & 42 \cdot 5 \\ 14 \cdot 6 & 40 \cdot 3\end{array}$

* Too small to measure accurately.

$\dagger$ Fermentation products ( $\mu$ mole $/ 100 \mu$ mole glycerol used): acetic acid, 17.9; propionic acid, 47.4; succinic acid, 31.7; lactic acid, 7.1. Carbon recovery $109 \%$.

$\mathbf{5 \cdot 3}$, depending on the glycerol concentration. As with the selenomonad cultures these results were not very reproducible because of the rapid decrease in turbidity after maximum growth, and this was accelerated by increasing the amount of glycerol in the medium. At glycerol 65.2 $\mu \mathrm{mole} / \mathrm{ml}$. all the glycerol was utilized, but 
at higher concentrations only a fraction was used. This might have been partly due to the $\mathrm{pH}$ value attained in the cultures. The carbon recovery showed that the fermentation products were accounted for and little glycerol carbon was utilized to form cellular material. Except at low values, the turbidity readings were related to mg. dry-weight organism/ml. (Fig. 4) in batch and continuous culture. The results of two continuous cultures, of 320 and $550 \mathrm{hr}$, are shown in Figs. 8, 9, 10. The turbidity readings are not corrected for growth in the basal medium since Fig. 4 does not show the same relationship between turbidity and dry weight of organisms at low and high turbidities and any correction would be very small and

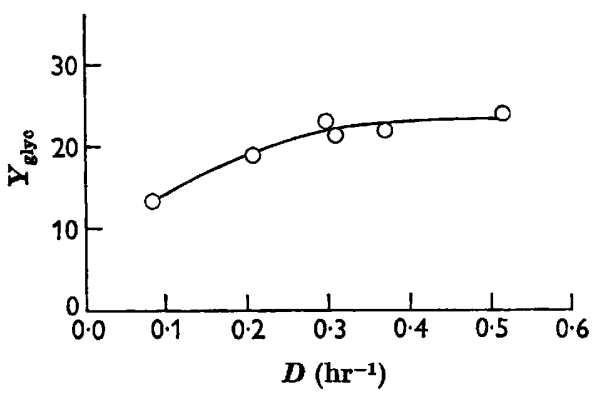

Fig. 9

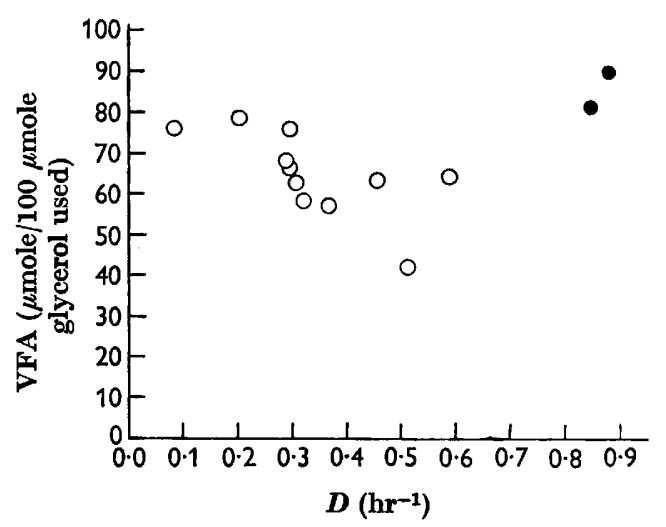

Fig, 10

Fig. 9. Continuous culture of lipolytic bacterium $5 \mathrm{~s}$; relationship between $Y_{\text {glyc }}$ and dilution rate $(D)$. Values are taken from two runs at a glycerol concentration of 65.6 $\mu \mathrm{mole} / \mathrm{ml}$. in the medium.

Fig. 10. Continuous culture of lipolytic bacterium $5 \mathrm{~s}$; relationship between VFA produced and dilution rate $(D)$. Values are taken from two runs at a glycerol concentration of $65.6 \mu \mathrm{mole} / \mathrm{ml}$. in the medium. At points marked a true steady state was not achieved (see Fig. 8).

uncertain in magnitude. Results from other cultures also gave graphs similar to Fig. 8, which is unlike the selenomonad results. The medium remained at about $\mathrm{pH} 6$ at dilution rates up to about $D=0.3$; above that it increased to $\mathrm{pH} 6.6$ at the highest dilution rate. Also included in Fig. 8 is a graph showing growth on the basal medium from one run of $190 \mathrm{hr}$. As in the case of selenomonad 6, the turbidity in continuous culture of bacterium $5 \mathrm{~s}$ was always less than in batch culture in the basal medium.

Bacterium 5s never showed granular growth like the selenomonad strain 6; growth was always uniformly turbid. Like the selenomonad the motility of bacterium $5 \mathrm{~s}$ was much greater in the continuous culture than in batch culture. When the $\mathrm{pH}$ value was suitable for growth the $5 \mathrm{~s}$ organisms were uniform in length and generally single, except at the highest dilution rates, when a few chains began to appear. However, in the cultures where the $\mathrm{pH}$ value was uncontrolled and the growth cycled, slowing down of growth as the $\mathrm{pH}$ value decreased was accompanied by the appearance of long coiled filaments of uniform diameter and of length up to about ten times the normal. These forms disappeared as the $\mathrm{pH}$ value increased 
again and growth re-started. Misshapen and spherical forms were also noted at low culture $\mathrm{pH}$ values when growth had stopped; these unnatural forms were commonly seen in batch cultures which had passed maximum growth.

\section{DISCUSSION}

The results of the present experiments show that it is possible to grow anaerobic rumen bacteria for prolonged periods in continuous culture. The cultivations reported here were done under carbohydrate-limiting conditions, but it would obviously be possible to use nitrogen-limiting conditions. The rumen is a kind of continuous culture, but apart from the fact that there is a wide diversity of microbial types present, it differs from the chemostat type of continuous culture described here in several ways, and, while the present results do give some pointers to the behaviour of rumen bacteria in vivo, it was not the purpose of these experiments to try to make an 'artificial rumen'. For instance, the rumen 'culture' has a very low dilution rate in vivo, only slightly more than one change of volume per day and, especially in the case of stall-fed animals, the micro-organisms do not attain a true steady state. Nutrient addition to the rumen, and to some extent saliva additions which form the main liquid flowing through the rumen, are intermittent and the concentrations of bacteria rise and fall in correspondence to these additions. Also, because of intermittent nutrient addition, it seems likely that different factors may limit bacterial growth at different times, and that the growth of all organisms will not be limited by the same nutrient. The change in amounts of fermentation products with growth rate, noted with the selenomonad strain 6 and to a lesser extent with the bacterium $5 \mathrm{~s}$ in continuous culture, suggests that the results of in vitro batch cultures may not always be a quantitative guide to fermentation in the rumen. Some change in products with growth rate has been noted with other bacteria, for example Streptococcus faecalis (Rosenberger \& Elsden, 1960). If the results here are any guide to happenings in vivo then the maximum growth rates of the bacteria have some significance. If the maximum growth rate is taken as that at the beginning of the washout portion of the curves, then the selenomonad strain 6 and bacterium $5 \mathrm{~s}$ have minimum doubling times $\left(\log _{e} 2 / D\right)$ of about $1 \cdot 4 \mathrm{hr}$. This is very much longer than that of $S$. bovis and shows how it is possible in some cases of overfeeding of carbohydrate for $S$. bovis to increase so rapidly as to become the predominant rumen bacterium in a matter of hours. The effect of $\mathrm{pH}$ value on the growth of bacterium $5 \mathrm{~s}$ is interesting (Fig. 2): at $\mathrm{pH}$ values below about 5.7 the growth rate markedly decreased, and growth appeared to cease at about $\mathrm{pH} 5 \cdot 3$. The $\mathrm{pH}$ value of rumen contents decreases after feeding and then increases and a value of $\mathrm{pH} \mathrm{5.7}$ is above the minimum found on some rations. For instance, Purser \& Moir (1959) and Bryant \& Robinson (1961 $b$ ) found minimum values of about $\mathrm{pH} 5.5$ and 5.6 in animals fed on concentrates at 2 to $4 \mathrm{hr}$ after feeding, compared with about $\mathrm{pH}$ $7 \cdot 0$ to $7 \cdot 2$ before feeding. Bryant \& Robinson's results show that viable bacterial numbers rapidly increased till just before the time of minimum $\mathrm{pH}$ value, while the pH remained above 6, and then decreased slowly. If the results of Fig. 2 are typical of the main types of rumen bacteria then it would seem that $\mathrm{pH}$ value is probably the factor which controls growth rate of the bacteria, especially in the first few hours after feeding, and not the substrate concentration. The changes in morphology 
of the selenomonad strain 6 and bacterium $5 \mathrm{~s}$ point to a limitation in the techniques of counting morphological types of rumen bacteria at different times after feeding. As previously pointed out (Hobson \& Mann, 1961) the selenomonads grown in vitro are much smaller than many seen in vivo, although there is a serological relationship between the organisms in vitro and in vivo (Hobson et al. 1962). One of the reasons for measuring the size of organisms in the selenomonad cultures was to see whether large forms were produced at high growth rates. Although the size of organism changed, no crescentic organisms of a size similar to that of those seen in the rumen were ever noted.

The theory of continuous culture proposed by Herbert et al. (1956) predicts that concentration of organism, equal to the maximum value found in batch culture, will not vary with growth rate until maximum growth rate (equated with dilution rate) is reached, but will then decrease rapidly. The limiting substrate concentration in the culture will generally remain very small until maximum growth rate is approached and will then increase rapidly. Some bacteria appear to behave in the theoretical manner, others diverge from the theoretical, but published data are scanty. A divergence at the higher growth rates, resulting in steady states at dilution rates apparently above the maximum growth rates and a slow decrease of concentration of organism as the dilution rate $(D)$ increases (e.g. Fig. 5) was attributed by Herbert et al. (1956) to inadequate mixing in the culture vessel. This is a possibility, but it seems to be a phenomenon generally found and more probably indicates an inadequacy in the present theoretical treatments. Further divergences from the theoretical curve of concentration of organism against dilution rate have been found at low dilution rates. A decrease in organism dry weight $/ \mathrm{ml}$. at low dilution rates, found under carbohydrate-limiting conditions by Herbert (1958) with Aerobacter aerogenes, was ascribed to endogenous metabolism of cell substance. Herbert suggested a change in the equations for continuous culture which might account for this theoretically. It is also possible to account for this decrease in concentration of organism at low growth rates by supposing that some of the substrate is fermented to provide maintenance energy, thus decreasing the substrate available for cell multiplication. This will have the greatest effect when growth rate is low. All the bacteria grown in the present experiments showed a decrease in concentration of organism at low growth rates. All graphs (Figs. 3, 5, 8) also showed a maximum value for bacterial concentration. Since this peak in the graphs occurred with all the bacteria it seems unlikely to be an artifact. What is very unusual are the graphs for the selenomonad strain 6 (Figs. 5, 6). These show not only a pronounced decrease in bacterial concentration at low growth rates, but a very high yield of organism at optimum growth rate. The yield of organism during an anaerobic fermentation has been linked with the energy available in the 'high-energy' phosphate bonds of ATP. Bauchop \& Elsden (1960) found that for some bacteria of known fermentation pathways growing in a medium containing preformed monomers a yield of about $10 \mathrm{~g}$. dry wt. organism/mole ATP ( $Y^{\mathrm{ATP}}$ ) produced during fermentation of the carbohydrate energy source was obtained. One of the bacteria tested by them, however, seemed to have a higher yield than could be accounted for by this method. Gunsalus \& Schuster (1961) calculated that the energy available in a mole of ATP is sufficient to polymerize monomers into $33 \mathrm{~g}$. of cell material, so that the experimental value of $Y^{\mathrm{ATP}}$ appears to be inefficient. 
The theoretical yield of organism per mole of carbohydrate fermented can be calculated for simple fermentations, but calculation becomes difficult for more complex fermentations.

The yield of organism, $Y_{\text {glye }}$, for bacterium $5 \mathrm{~s}$ growing on glycerol approximates to 22 at the optimum growth rates in continuous culture and in batch culture where glycerol is limiting. At higher glycerol concentrations in batch culture $\boldsymbol{Y}_{\text {glyc }}$ decreases because fermentation of glycerol continues after growth is limited by a nitrogenous, or other, constituent of the medium, or by the decrease in $\mathrm{pH}$ value of the culture. The energy available in fermentation at this stage might be released by an ATPase type of enzyme, or might be used for maintenance of the organisms, although in this latter case the $\mathrm{pH}$ value (or other conditions in the medium) seems to be such that lysis of organisms takes place more rapidly than their structure can be maintained. The value of $Y_{\mathrm{glyc}}$ found for bacterium $5 \mathrm{~s}$ approximates to formation of 2 ATP molecules during the fermentation (on the basis of $Y^{\text {ATP }}=10$ ) and is in agreement with the results of Bauchop \& Elsden (1960) with a Propionibacterium fermenting glycerol.

The yield of selenomonads ( $Y_{\text {gluc }}$ ), though, is about 62 at optimum growth rates (taking the average of values between the lines in Fig. 6). This would correspond to the formation of about 5-6 mole ATP/mole of glucose fermented. This seems improbable on present concepts of the pathways of fermentation. However, consideration of all the results suggests that the high yield is unlikely to be due to fermentation of the amino acids of the basal medium, or a secondary fermentation of lactate, and it must be concluded that this value is actually $\boldsymbol{Y}_{\text {gluc }}$ for this bacterium. There then remain the two possibilities that the selenomonads have sources of energy for growth other than those so far found in known modes of fermentation, or that $Y^{\Delta T P}$ is not universally 10 , but is greater for some anaerobes. While this paper was being written Hungate (1963) reported that a strain of Ruminococcus albus growing in a continuous culture at a dilution rate of $0.1 \mathrm{hr}^{-1}$ on cellobiose gave a value for $Y_{\text {gluc }}$ of 55. This high yield was unexplained. The maximum value for $\boldsymbol{Y}_{\text {gluc }}$ calculated from the different batch cultures of the selenomonad approximates to 20, suggesting an ATP formation of 2 mole/mole glucose fermented on the basis of $Y^{\mathbf{A T P}}=10$. This appears reasonable, but since the yield of the selenomonad varies with growth rate in continuous culture it can be shown that the apparent yield of the batch cultures is probably entirely fortuitous, and hears no relationship to the actual yields under optimum growth conditions.

The author wishes to thank Mr W. Smith for assistance during these experiments.

\section{REFERENCES}

Bauchop, T. \& Elsden, S. R. (1960). The growth of micro-organisms in relation to their energy supply. J. gen. Microbiol. 23, 457.

Bisset, K. A. \& Davis, G. H. G. (1960). In The Microbial Flora of the Mouth. London: Heywood and Co.

Bryant, M. P. \& Robinson, I. M. (1961 a). Some nutritional requirements of the genus Ruminococcus. Appl. Microbiol. 9, 91.

Bryant, M. P. \& Robinson, I. M. (1961b). An improved non-selective culture medium for ruminal bacteria and its use in determining diurnal variation in numbers of bacteria in the rumen. J. Dairy Sci. 44, 1446. 
Finn, R. K. \& Wilson, R. E. (1954). Population dynamics of a continuous propagator for micro-organisms. J. Agric. Fd Chem. $2,66$.

Gunsalus, C. \& Schuster, C. W. (1961). Energy-yielding metabolism in bacteria, in The Bacteria, vol. 2. New York: Academic Press.

Hanahan, D. J. \& Olley, J. N. (1958). Chemical nature of monophosphoinositides. $J$. biol. Chem. 231, 813.

Herbert, D. (1958). In Recent Progress in Microbiology, VII Intern. Congr. for Microbiology, Stockholm.

Herbert, D., Elsworth, R. \& Teluing, R. C. (1956). The continuous culture of bacteria; a theoretical and experimental study. J. gen. Microbiol. 14, 601.

Hobson, P. N. (1965). Continuous culture of rumen bacteria: apparatus. J. gen. Microbiol. 38, 161.

Hobson, P. N. \& MaNN, S. O. (1955). Some factors affecting the formation of iodophilic polysaccharide in group D streptococci from the rumen. J. gen. Microbiol. 13, 420.

Hobson, P. N. \& ManN, S. O. (1961). The isolation of glycerol-fermenting and lipolytic bacteria from the rumen of the sheep. J. gen. Microbiol. 25, 227.

Hobson, P. N., ManN, S. O. \& SMrth, W. (1962). Serological tests of a relationship between rumen selenomonads in vitro and in vivo. J. gen. Microbiol. 29, 265.

Hungate, R. E. (1963). Polysaccharide storage and growth efficiency in Ruminococcus albus. J. Bact. 86, 848.

Purser, D. B. \& MoIr, R. J. (1959). The effect of $\mathrm{pH}$ on the ciliate population of the rumen in vivo. Aust. J. agric. Res. $10,555$.

Rosenberger, R. F. \& Elsden, S. R. (1960). The yields of Streptococcus faecalis grown in continuous culture. J. gen. Microbiol. 22, 726.

Wiseman, H. G. \& Irwin, H. M. (1957). Determination of organic acids in silage. $J$. Agric. Fd Chem. 5, 213. 